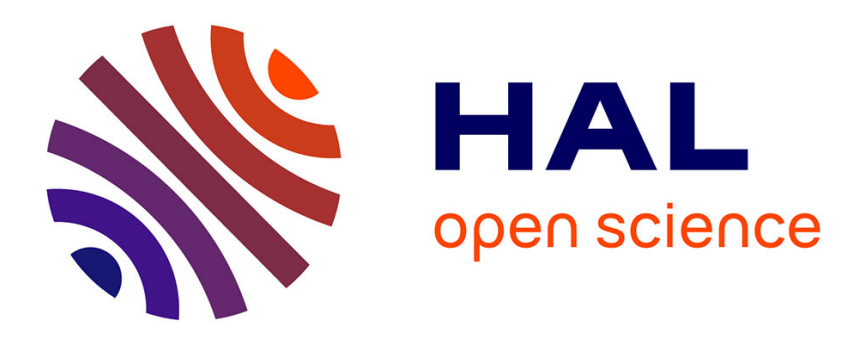

\title{
Spallation of glass materials under laser induced shocks
}

\author{
T. de Resseguier, F. Cottet
}

\section{To cite this version:}

T. de Resseguier, F. Cottet. Spallation of glass materials under laser induced shocks. Journal de Physique IV Proceedings, 1994, 04 (C8), pp.C8-629-C8-634. 10.1051/jp4:1994895 . jpa-00253456

\section{HAL Id: jpa-00253456 https://hal.science/jpa-00253456}

Submitted on 1 Jan 1994

HAL is a multi-disciplinary open access archive for the deposit and dissemination of scientific research documents, whether they are published or not. The documents may come from teaching and research institutions in France or abroad, or from public or private research centers.
L'archive ouverte pluridisciplinaire HAL, est destinée au dépôt et à la diffusion de documents scientifiques de niveau recherche, publiés ou non, émanant des établissements d'enseignement et de recherche français ou étrangers, des laboratoires publics ou privés. 
JOURNAL DE PHYSIQUE IV

Colloque C8, supplément au Journal de Physique III, Volume 4, septembre 1994

\title{
Spallation of glass materials under laser induced shocks
}

\author{
T. de Rességuier and F. Cottet
}

LED-ENSMA, rue Guillaume VII, 86034 Poitiers cedex, France

\begin{abstract}
résumé : L'étude de l'écaillage des matériaux de type verre est rendue difficile par leur grande fragilité, qui entraine la destruction quasi-totale des échantillons testés sous chocs conventionnels. La très courte durée des chocs générés par irradiation laser limite cette destruction, et permet une étude originale, basée sur l'examen post-mortem des cibles endommagées. L'écaillage se traduit par la formation d'une zone fracturée, dont l'épaisseur dépend des paramètres expérimentaux. Une description macroscopique de cette fragmentation est proposée. Un modèle phénoménologique simple, implémenté dans un code de calcul monodimensionnel, permet de prédire approximativement l'étendue de la zone fracturée dans une cible de verre sodo-calcique soumise à un choc-laser de courte durée.
\end{abstract}

abstract : The investigation of spallation in brittle materials like glass is usually limited by the severe destruction of the specimens. In this paper, an original study of this phenomenon, based on the post-shock examination of damaged targets, is presented. A high-power pulsed laser is used to generate very short compressive pulses in glass plates. A fractured layer is observed near the free surface of the recovered samples. The influences of the experimental parameters upon the thickness of this layer are evaluated. Then, a simple macroscopic description for spallation in glass is proposed. The resulting model, implemented in a one-dimensional simulation code, can predict the extent of the damage induced in a soda-lime glass target by a laser-driven shock.

\section{INTRODUCTION.}

When a solid specimen is submitted to a dynamic loading at high strain rate, an internal failure process called spallation can occur. This phenomenon, playing a major role in any application involving shocks (impact of a micrometeorite on a spacecraft, ballistic impact on an armor, ... ), has been widely studied in both ductile $[1,2]$ and brittle $[3,4]$ materials. In very brittle materials such as glass, the use of traditional shock techniques (explosive or impact of a projectile ) leads to an almost complete destruction of the target. Therefore, the recovery of shocked samples is hardly possible, and most of the results reported on the subject are based on measurements ( particle velocity, stresses ) obtained during the tests. This paper presents a study of spall fracture in soda-lime glass, using a high-power pulsed laser as a shock-wave generator. The very short durations of laser-driven shocks ( a few nanoseconds) are shown to result in a limited destruction of the samples. A post-shock examination of the targets is carried out and the influences of the main parameters upon the damage are analyzed. On the basis of these observations, a simple description of spallation in glass is proposed. This description is implemented in a numerical model, in order to simulate glass targets submitted to one-dimensional (1-D) dynamic loading. Finally, the ability of the model to reproduce the experimental data is tested. 


\section{EXPERIMENTAL STUDY.}

\subsection{Laser-driven shock loading}

All experiments have been carried out in the Laboratoire pour l'Utilisation des Lasers Intenses, at Ecole Polytechnique. Some characteristics of the soda-lime glass are given in table I. The fundamental wave length of the Nd-glass laser is $1.06 \mu \mathrm{m}$. A thin layer of silver, approximately $1 \mu \mathrm{m}$-thick, was deposited on the front surface of the glass targets. When the laser beam is focused onto this surface, the silver coating is ablated, a plasma cloud evaporates, and its blow-off induces a shock in the glass, due to recoil action. The variations of the applied pressure with time follow approximately the gaussian shape of the laser pulse. The peak pressure $\mathrm{P}_{M}$ depends on the absorbed flux $\mathrm{I}_{a}$, which is about $80 \%$ of the incident flux in our conditions [2]. On our experimental range $\left(I_{a}\right.$ varying between $10^{2}$ and $\left.10^{4} \mathrm{GW}^{-\mathrm{cm}^{-2}}\right)$, $P_{M}$ is given by the following law $[2,5]$ :

$$
\begin{aligned}
& P_{M}=12 I_{a} 2 / 3 \\
& \text { where } I_{a} \text { is in } 10^{2} \mathrm{GW} . \mathrm{cm}^{-2} \text { and } P_{M} \text { is in GPa. }
\end{aligned}
$$

The pulse duration is defined as $\tau$, the full width at half the maximum. Three different durations have been used : $0.6 \mathrm{~ns}, 2.4 \mathrm{~ns}$, and $27 \mathrm{~ns}$. The average output energy of the laser was about $70 \mathrm{~J}$. The targets were settled in a vacuum chamber to avoid the laser breakdown in the air. As long as the diameter of the irradiated focal spot is greater than the target thickness, we assume that the loading results in the planar propagation of a compressive pulse in the glass plate, in the vicinity of the axis of the laser. Thus, the 2-D effects that could come from radial inhomogeneities of the energy distribution in the beam are disregarded.

\subsection{Post-shock examination of recovered samples}

Depending on the incident flux, the recovered samples can present different features :

- For very high intensities, above $600 \mathrm{GW} . \mathrm{cm}^{-2}$, the glass targets are damaged on both faces. These intensities correspond to small focal spots, which require small target thicknesses to allow a 1-D description. In such cases, the damage is too severe to permit a meaningful analysis.

- For lower intensities, the front surface of the glass target seems intact. On the rear free surface, depending on the experimental conditions, two situations can be observed :

- for low intensities or thick targets, the sample seems totally unaffected by the shock.

- for higher intensities or thinner targets (typically $300 \mathrm{GW} \cdot \mathrm{cm}^{-2}$ and $2 \mathrm{~mm}$ ), the rear surface presents a crater, corresponding to the ejection of a scab, characteristic of the spallation phenomenon.

The recovered samples belonging to the latter category ( no apparent damage on the irradiated surface and crater on the rear surface ) have been coated with resin, cut and polished through a plane containing the axis of the laser beam, then the cross sections have been scanned by optical microscopy. As shown on figure 1, a fractured layer was observed near the rear free surface of these samples. Thus, laser-induced spall fracture in glass occurs over a zone of finite thickness, not in a plane as in ductile materials. In most cases, the cracks in the fractured zone are roughly contained in parallel planes, perpendicular to the laser beam, at least in the vicinity of the axis of this beam. This suggests that the approximation of a plane stress front in this area is probably correct before and until tensile failure occurs. On the contrary, the orientations of the cracks located at the periphery, further from the axis, indicate a highly two-dimensional stress field, depending on complex edge effects.

\subsection{Influences of the experimental parameters on the damage}

The thickness $Z_{F}$ of the fractured zone has been measured in each spalled target ( see figure 2 ), and the influences of the main experimental parameters ( the target thickness $T_{t}$, the peak pressure $P_{M}$ and the pulse duration $\tau$ ) upon this thickness have been determined.

TABLE I : Main characteristics of soda-lime glass.

\begin{tabular}{|c|c|c|c|}
\hline \multicolumn{2}{|c|}{ physical properties } & \multicolumn{2}{c|}{ main components } \\
\hline density & $2512 \mathrm{~kg} \cdot \mathrm{m}-3$ & $\mathrm{SiO} 2$ & $71.5 \%$ \\
longitudinal sound speed & $5760 \mathrm{~m} . \mathrm{s}-1$ & $\mathrm{Na2O}$ & $13.7 \%$ \\
transverse sound speed & $3390 \mathrm{~m} . \mathrm{s}-1$ & $\mathrm{CaO}$ & $9.5 \%$ \\
\hline
\end{tabular}




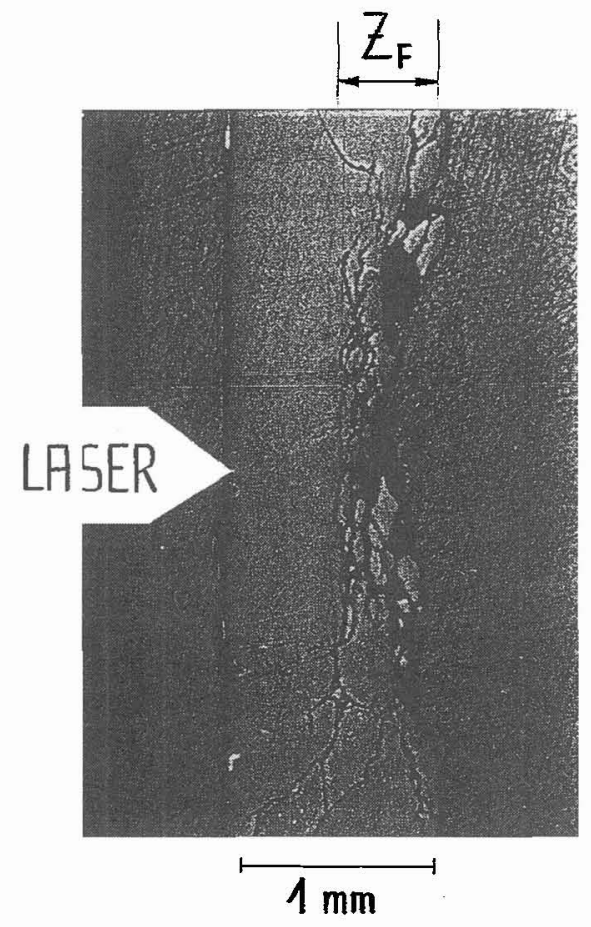

FIG. 1. Optical photomicrograph of the cross section of a soda-lime glass target recovered after a laser shock, showing a fractured layer near the rear free surface of the specimen. The pulse duration was $0.6 \mathrm{~ns}$ and the absorbed intensity was $440 \mathrm{GW} . \mathrm{cm}^{-2}$.

Figure 2 shows the variations of $\mathrm{Z}_{\mathrm{F}}$ versus $\mathrm{P}_{\mathrm{M}}$, for a pulse duration of 2.4 ns and various target thicknesses. The amplitude of the compressive pulse which propagates in the target increases with $\mathrm{P}_{\mathrm{M}}$, so that when this pulse reflects into tension on the rear free surface, the tensile stress induced in the glass will be higher for a higher value of $\mathrm{P}_{\mathrm{M}}$. The resuiting damage will be more severe. Hence, $Z_{\mathrm{F}}$ increases with $\mathrm{P}_{\mathrm{M}}$. Above a threshold pressure of about $30 \mathrm{GPa}$, this trend becomes much smoother. This is due to the decay of the incident pulse when it travels through the glass target. Indeed, one property of glass behaviour is that this decay is very rapid near the front surface, then it slows down to give rise to an approximately steady elastic pulse. Therefore, increasing $P_{M}$ on the front surface above a certain limit does not affect much the final pulse on the rear surface. This rapid attenuation also accounts for the small influence of $T_{t}$. On our pressure range, an almost steady pulse will be produced after propagation through $\sim 1 \mathrm{~mm}$, so the loading induced near the rear surface will not differ much from a thin target to a thick one.

The effect of the pulse duration is hard to isolate from the one of the peak pressure, because both are directly related to the incident flux. However, comparisons between spalled targets, for two short durations 0.6 and $2.4 \mathrm{~ns}$, the other parameters being approximately constant, show that $\mathrm{Z}_{\mathrm{F}}$ increases with $\tau$. Indeed, a shorter pulse will attenuate more rapidly than a longer one, so that the spalled zone near the rear face of the target will be thinner. For longer pulses of $27 \mathrm{~ns}$ and similar pressures, we could not recover any of the irradiated samples, which always broke in small pieces. We believe that in such cases, the impulse momentum delivered to the target by the laser shock, which is proportional to the pulse duration, produces the failure of the specimen due to the shear stresses generated on its edges, maintained in a fixed support. For lower pressures, below $8 \mathrm{GPa}$, no spallation was observed.

\section{NUMERICAL STUDY.}

\subsection{The code and the constitutive model}

The response of the glass to shock loading has been modeled. The model has been implemented in the code SHYLAC ( Shock HYdrodynamic LAgrangian Code ) [2], able to simulate the 1-D propagation of shock waves through solid materials. The laser-matter interaction is not treated explicitly, but the shock conditions corresponding to a laser irradiation can be simulated through the application on the target of the gaussian pressure pulse described in section 2.1. 


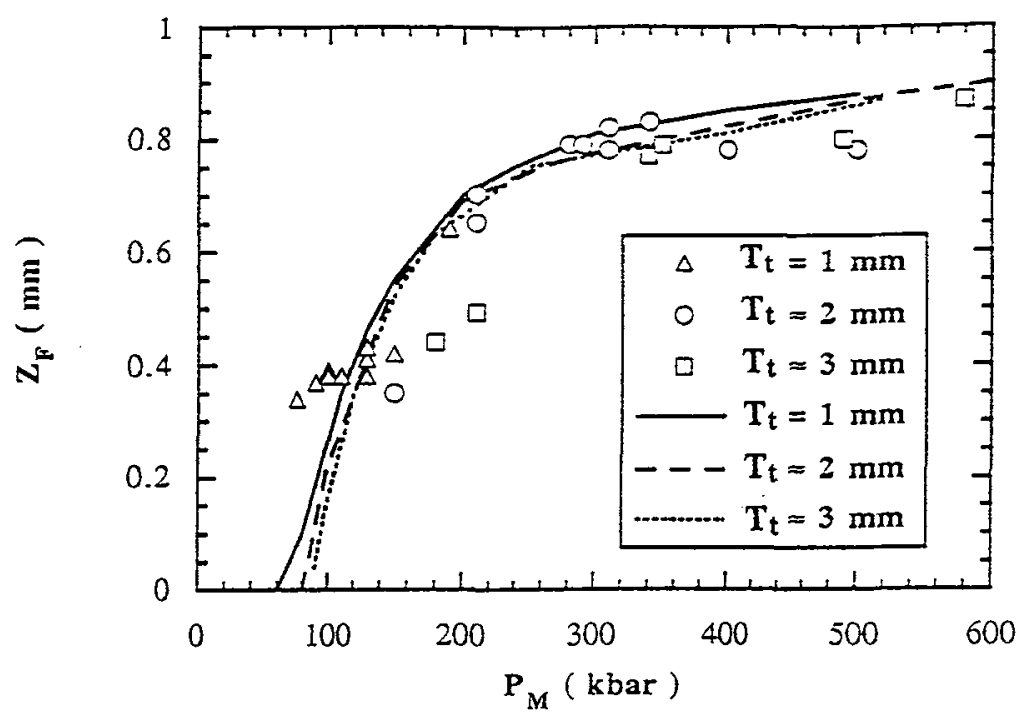

FIG. 2. Experimental results (dots ) in soda-lime glass, showing the variations of the thickness of the fractured zone versus the applied peak pressure, for several target thicknesses and a pulse duration of $2.4 \mathrm{~ns}$. The lines show the results predicted by the model described in section 3 .

In a previous study, a specific description of glass behaviour under 1-D compression has been developed, on the basis of experimental results obtained under explosive loading, completed with data from the literature [6]. The resulting model assumes an elastic response of the material up to a threshold stress, above which a permanent densification of the glass occurs. It has been shown able to reproduce reasonably well the deformation of the compressive fronts during their propagation through the samples, over a wide range of stresses, and its predictions for the release paths in the glass are consistent with data from the literature. This model has been applied to simulate the 1-D propagation of laser-driven shocks in soda-lime glass, and a phenomenological description of brittle spall fracture has been included in it.

\subsection{The spall model}

Our approach is based on a macroscopic description of the spallation phenomenon. Thus, the damage is defined locally in each material element as the relative volume of microvoids :

$$
D(X, t)=V_{V} / V=1-V_{S} / V
$$

where $D$ is the damage function, $X$ is the distance from the irradiated surface in the direction of shock propagation, $t$ is the time, $V_{v}$ is the volume of the microvoids in the damaged material, $V_{S}$ is the solid volume in the cell, and $\mathrm{V}$ is the total volume of the cell. Therefore, $\mathrm{D}$ varies continuously from 0 in an intact element to 1 when complete rupture occurs in the element. Equation (2) defines the overall damage as a porosity, which increases under sufficient tensile loading. Thus, a coupling relationship between the damage and the applied stress can be inferred, as it is usually done in porous materials [7] :

$$
\sigma=\sigma_{\mathrm{S}}(1-\mathrm{D})
$$

where $\sigma$ is the effective stress induced in the damaged element, and $\sigma_{\mathrm{S}}$ is the stress applied to the solid fraction of the element, i.e. the stress calculated with the equation of state of the undamaged glass. This expression introduces a progressive relaxation of the tensile stresses induced in the sample when spall damage is produced.

Then, an evolution law for D is proposed, based on the classical criterion of Tuler \& Butcher [8], which was shown to fit successfully experimental data obtained in ductile materials under our loading conditions ${ }^{[2]}$. This cumulative damage criterion can be written as follows : 


$$
\begin{array}{ll}
\dot{\mathrm{D}}=\frac{1}{\mathrm{~K}}\left(\sigma-\sigma_{\mathrm{c}}\right)^{\mathrm{a}} & \text { if } \sigma>\sigma_{\mathrm{c}} \\
\dot{\mathrm{D}}=0 & \text { if } \sigma \leq \sigma_{\mathrm{c}}
\end{array}
$$

where a and $\mathrm{K}$ are phenomenological constants characteristic of the material, $\sigma$ is the tensile stress, positive in tension, and $\sigma_{\mathrm{c}}$ is the maximum tensile stress that the material can bear without being damaged. In this original formulation, $\sigma_{\mathfrak{c}}$ was assumed to be a material constant. However, as far as brittle fracture is concerned, it is a well-known feature that the tensile stress needed to propagate a crack decreases with the size of this crack. Therefore, we assume that the tensile strength of the material in a given element decreases while this element is being damaged. Thus, a simple expression meeting this requirement has been added to the former criterion :

$$
\sigma_{\mathrm{c}}=\sigma_{0}(1-\mathrm{D})^{\mathrm{b}}
$$

where $\sigma_{0}$ is the spall strength of the intact material, and $b$ is a material constant.

\subsection{Identification of the model constants and validation of the model}

In accordance with other models, the phenomenological parameter a has been chosen as $1[9,10]$. In order to determine the other constants $\mathrm{K}, \sigma_{0}$, and $\mathrm{b}$, simulations of laser shocks on glass have been performed ( see figure 3 ). They show the formation of a damaged zone near the rear free surface of the target, together with the progressive relaxation of the tensile pulse reflected from this surface. At the end of the calculation, this pulse is highly attenuated, and the damage stops growing. Then, if one assumes that the minimum damage observable in optical microscopy corresponds to a threshold value $\mathrm{D}_{0}=0.2$, one can compare the thickness of the zone where $D \geq D_{0}$ to the experimental value $Z_{F}$ measured on the cross section. The constants $K, \sigma_{0}$ and $b$ have been adjusted on the basis of such comparisons, to match the calculated and measured thicknesses of the fractured layer, respectively $\mathrm{Z}_{\mathrm{Fsim}}$ and $\mathrm{Z}_{\mathrm{Fexp}}$. For this determination, three experiments have been chosen. One revealed no apparent damage. The other two correspond to cases for which the spalled layer indicated a good planarity of the shock front. The conditions associated with these tests are given in table II, which also shows a correct agreement on $\mathrm{Z}_{\mathrm{F}}$ for: $\mathrm{K}=5000 \mathrm{GPa} . \mathrm{s} ; \sigma_{0}=0.8 \mathrm{GPa} ; \mathrm{b}=3$.

The ability of the model to reproduce experimental results has been tested over the whole range of experiments. Figure 3 shows its predictions for $\tau=2.4 \mathrm{~ns}$, in targets of various thicknesses. The small influence of $T_{t}$ upon the fractured zone is well reproduced, as well as the stronger effect of PM. Table III shows the results obtained for shorter pulses of $0.6 \mathrm{~ns}$, and reveals a poorer agreement. This discrepancy can result from a lack of accuracy in the constitutive model, which would lead to an erroneous attenuation of the incident pulse as it travels through the glass sample. This effect would be critical for very short pulses, when attenuation plays an essential role. Another possible error could come from the estimated pressure pulse duration. Indeed, it could be slightly longer than the laser pulse duration $\tau$. Further work in this direction is needed to characterize the loading induced by the laser irradiation. Finally, the lack of experimental data in the $27 \mathrm{~ns}$ range does not permit to test the model for such long pulses.

\section{CONCLUSION.}

An original study of spallation in glass under laser-driven shocks has been carried out through the post-shock examination of spalled samples. This has been possible thanks to the very short durations of laser shocks, which lead to a reduced destruction of the targets, as compared to classical shock techniques. Thus, high-power pulsed lasers appear as a useful tool to characterize the damage in brittle materials under dynamic loading. In our experimental conditions, spall fracture has been shown to result in the formation of a fractured layer near the rear surface of the glass targets. A macroscopic description of this phenomenon, based on a cumulative damage criterion completed with simple assumptions, has been implemented in a 1-D simulation code, and coupled with a specific constitutive model for soda-lime glass. For a pulse duration of $2.4 \mathrm{~ns}$, this phenomenological model is able to predict correctly the finite thickness of the fractured zone, in glass targets of various thicknesses, on a wide range of peak loading pressures. For shorter pulses of $0.6 \mathrm{~ns}$, it provides an estimate of this thickness. 
damage (a)

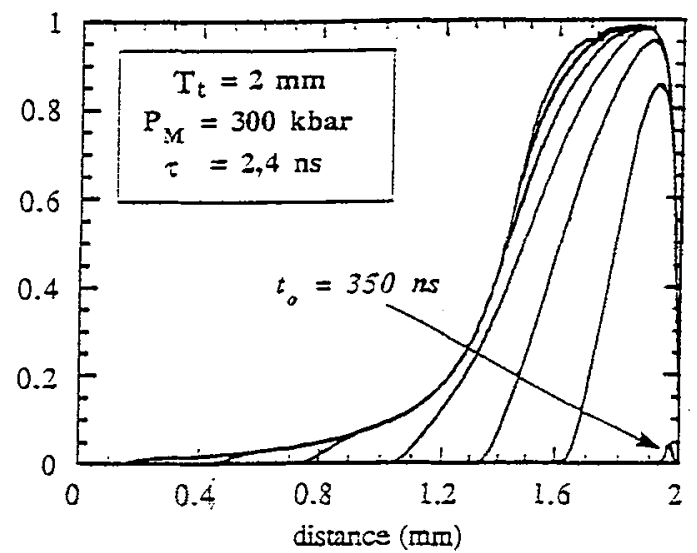

compressive stress (b)

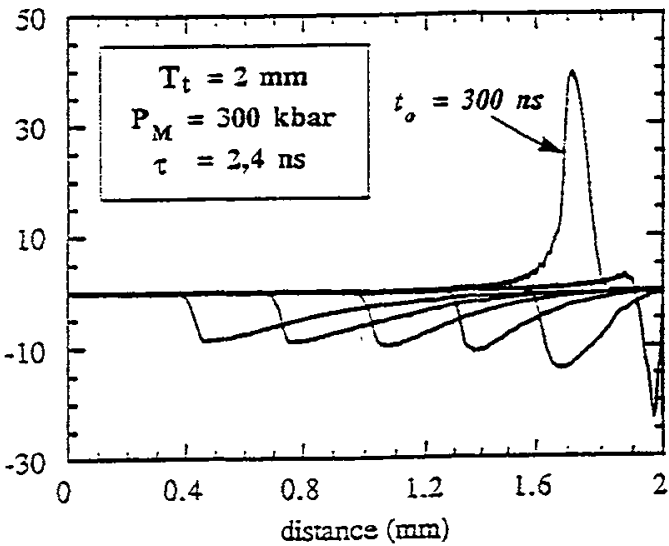

FIG. 3. Simulation of the spall failure of a $2 \mathrm{~mm}$-thick glass target, under a laser shock of amplitude $300 \mathrm{kbar}$ and duration $2.4 \mathrm{~ns}$. Damage (a) and stress (b) distributions in the target are plotted every $50 \mathrm{~ns}$, starting at time to.

TABLE II : Identification of the model constants, based on three specific tests ; the final values used in the simulation are $: K=5000 \mathrm{GPa} . \mathrm{s}, \sigma_{0}=0.8 \mathrm{GPa}$, and $\mathrm{b}=3$.

\begin{tabular}{|c|c|c|c|c|}
\hline target & peak & pulse & \multicolumn{2}{|c|}{ thickness of the fractured layer } \\
\cline { 4 - 5 } thickness & pressure & duration & experiment & simulation \\
\hline $2.0 \mathrm{~mm}$ & $8 \mathrm{GPa}$ & $2.4 \mathrm{~ns}$ & 0 & 0 \\
$2.1 \mathrm{~mm}$ & $29 \mathrm{GPa}$ & $2.4 \mathrm{~ns}$ & $0.79 \mathrm{~mm}$ & $0.77 \mathrm{~mm}$ \\
$1.0 \mathrm{~mm}$ & $11 \mathrm{GPa}$ & $2.4 \mathrm{~ns}$ & $0.32 \mathrm{~mm}$ & $0.35 \mathrm{~mm}$ \\
\hline
\end{tabular}

TABLE III : Comparison between the calculated and measured values of $\mathrm{Z}_{\mathrm{F}}$ for pulses of $0.6 \mathrm{~ns}$.

\begin{tabular}{|c|c|c|c|}
\hline peak pressure $\mathbf{P}_{M}$ & target thickness $\mathbf{T}_{\mathbf{t}}$ & $\mathrm{Z}_{\mathrm{F}}(\mathrm{exp})$ & $\mathrm{Z}_{\mathrm{F}}(\mathrm{sim})$ \\
\hline $32 \mathrm{GPa}$ & $1.1 \mathrm{~mm}$ & $0.49 \mathrm{~mm}$ & $0.15 \mathrm{~mm}$ \\
$68 \mathrm{GPa}$ & $2.1 \mathrm{~mm}$ & $0.72 \mathrm{~mm}$ & $0.62 \mathrm{~mm}$ \\
$68 \mathrm{GPa}$ & $1.6 \mathrm{~mm}$ & $0.74 \mathrm{~mm}$ & $0.63 \mathrm{~mm}$ \\
\hline
\end{tabular}

\section{REFERENCES}

[1] R.G. Mc Queen, S.P. Marsh, J. Appl. Phys. 33, 654 (1962).

[2] F. Cottet and M. Boustie, J. Appl. Phys. 66(9), 4067 (1989).

[3] G.I. Kanel, A.M. Molodets and A.N. Dremin, Combustion Explos. Shock Waves 13, 772 (1977).

[4] D.E. Grady, J. Mech. Phys. Solids 36(3), 353 (1988).

[5] F. Cottet, These de Doctorat, Universite de Poitiers (1985).

[6] T. de Resseguier, These de Doctorat, Universite de Poitiers (1993).

[7] M.M. Caroll and A.C. Holt, J. Appl. Phys. 43(4), 1626 (1972).

[8] F.R. Tuler, B.M. Butcher, Int. J. Fract. Mech. 6(2), 169 (1970).

[9] L. Seaman, D. Curran, D. Shockey, J. Appl. Phys. 47(11), 4814 (1976).

[10] J. Cagnoux, High Pressure Science and Technology, Proc. VIIth Int. AIRAPT Conference, Vol.2, 1022 (1979). 